\title{
Recording of atmospheric electrical potential gradient in the central part of Kamchatka peninsula
}

\author{
Rinat Akbashev ${ }^{11^{*}}$, Pavel Firstov ${ }^{1,2}$ and Nina Cherneva ${ }^{2}$ \\ ${ }^{1}$ Kamchatkan Branch of the Federal Research Center "United Geophysical Service of the RAS", \\ Russia \\ ${ }^{2}$ Institute of Cosmophysical Research and Radio Wave Propagation FEB RAS, Russia
}

\begin{abstract}
Electrostatic fluxmeters are in operation at three sites in the region of Central Kamchatka depression to record the atmospheric electrical potential gradient (PG). PG diurnal variations for these sites are compared with those of «Paratunka» observatory (PRT) located on the Eastern coast of Kamchatka peninsula. Cases of the response in AEV $V^{\prime}$ dynamics on eruptive cloud passage, occurring during Shiveluch volcano explosive eruptions, are described. Negative polarity signals with the maximum values up to $5 \mathrm{kV} / \mathrm{m}$ were recorded in the near-field zone $(<50 \mathrm{~km})$ during ash fall. Positive polarity signals were recorded in the far-field zone $(>100 \mathrm{~km})$. Recording of signals in PG occurring during eruptive cloud passage may be one of the components of complex observations over volcanic eruptions ${ }^{2 * *}$.
\end{abstract}

\section{Introduction}

The atmospheric electric field (AEF) phenomenon was first discovered and described in the middle of the 18-th century. At that time theoretical basis for these investigations were formed by the ideas of famous scientists such as Lomonosov, Franklin, Dolibar, Richmann, Lemonnier.

According to modern conceptions, AEF is associated with multiple processes occurring in the Earth's atmosphere, ionosphere and magnetosphere united by the common notion, the Global Electrical Circuit (GEC). It is know that GEC implies the existence of a distributed loop with «generators», the role of which is fulfilled by planetary lightning processes, and with «fair» weather regions in which GEC energy dissipates. The upper part of the loop is the ionosphere. Owing to conductivity, the Earth's surface serves as the lower part of GEC loop. Based on present-day estimates, the potential between the clouds of such a «condenser» is $180-400 \mathrm{kV}$, and the total current between the ionosphere and the Earth's surface reaches 800-1800 A.

When investigating atmospheric electric field in fair weather conditions that means absence of lightning, precipitation, fogs etc., it was determined that AEF has such a direction as if the Earth is negatively charge and the atmosphere is positively charged [1]. Consequently, the value characterizing AEF value at a definite height from the Earth's surface, is called AEF intensity. A reciprocal value is called the atmospheric electrical potential gradient (PG). The PG average value by the Earth's surface is about $120 \mathrm{~V} / \mathrm{m}$ over the continents and $80-90 \mathrm{~V} / \mathrm{m}$ over the ocean surface [2]. The key achievements in the

\footnotetext{
*Corresponding author: $\operatorname{arr} @$ emsd.ru

*** The work was supported by RFBR Grant No.18-35-00175.
} 
investigation of fair weather electrification were obtained by the measurements carried out at Carnegie Institute in Washington at the beginning of the XX-th century. Thus, the main result of field intensity measurements over oceans on "Carnegie» ship was the detection of maxima and minima in electric field intensity diurnal variation. The maximum is observed stably at about 19 o'clock according to Greenwich Mean Time (Universal Time), and the minimum was observed at 3 o'clock. The variation repeated over the Indian, Atlantic and Pacific Oceans and in the Polar Regions.

Thus, close correlation of GEC with Carnegie curve (diurnal variation) was detected that was also noted in the papers [3,4] Nevertheless, this phenomenon requires further research to give additional information for GEC behaviour interpretation. To do that, continuous monitoring of electric field at different geographical regions is required.

On the other part, AEF is also determined by local factors of both anthropogenic character, such as air pollution (and, as a consequence, air conductivity change) and natural character such as sunrise effect, fog, volcanic eruptions, dust and snow storms. Local factors cause significant PG disturbances, the values of which during a maximum may exceed the first units of $\mathrm{kV} / \mathrm{m}$, and have different polarity. Such factors also contribute to GEC and require further research along with lightning phenomena [5].

Kamchatka peninsula is unique ground to investigate atmospheric-electric effects associated with lithosphere and atmosphere interaction determined by such geodynamic processes as earthquakes and volcanic eruptions. Four the most active volcanoes of Kamchatka peninsula form the Northern Group, they are: Shiveluch, Klyuchevskoy, Bezymyanniy and Ploskiy Tolbachik volcanoes. An electrostatic fluxmeter «EF-4» is used to record PG near this group of volcanoes at Klyuchi (KLYG) and Kozyrevsk (KZYG) villages. This instrument is described in the paper [6]. Along with traditional tasks of atmospheric electricity (investigation of unitary variation, GEC mechanisms etc.), this allows us to study atmospheric-electric effects occurring during formation and propagation of ash-gas clouds from volcanic explosive eruptions.

The paper gives a description of unitary variation of the central part of Kamchatka with its manifestation on the Eastern coas. It also considers the PG response during the passage of volcanic clouds from strong explosive eruptions of Shiveluch volcano in 2014-2017.

\section{Observation instrumentation and system}

PG is recorded at Kamchatkan Branch of the Federal Research Center "United Geophysical Service of the RAS" at three sites in Kozyrevsk, Klyuchi and Ust'-Kamchatsk (Fig. 1a).

Continuous recording of AEF data is carried out by a hardware complex including electrostatic sensor «EF-4» (Fib. 1b.), analog-to-digital converter and a computer (laptop) with software. The data are stored on a hard disk of the computer with the recording frequency of $100 \mathrm{~Hz}$ (Fig. 1c). At present time, a software-hardware complex has been developed based on ADC L-Card E-24 and microcomputers of ThinerBoard series by Asus. The developed complex with the microcomputer provides remote access to the software part of the complex located at outstations and allows us to adjust the instrumentation without physical access that improves the work efficiency. The software part of the complex is realized in Python language, modern high-level computer language of general purpose. 

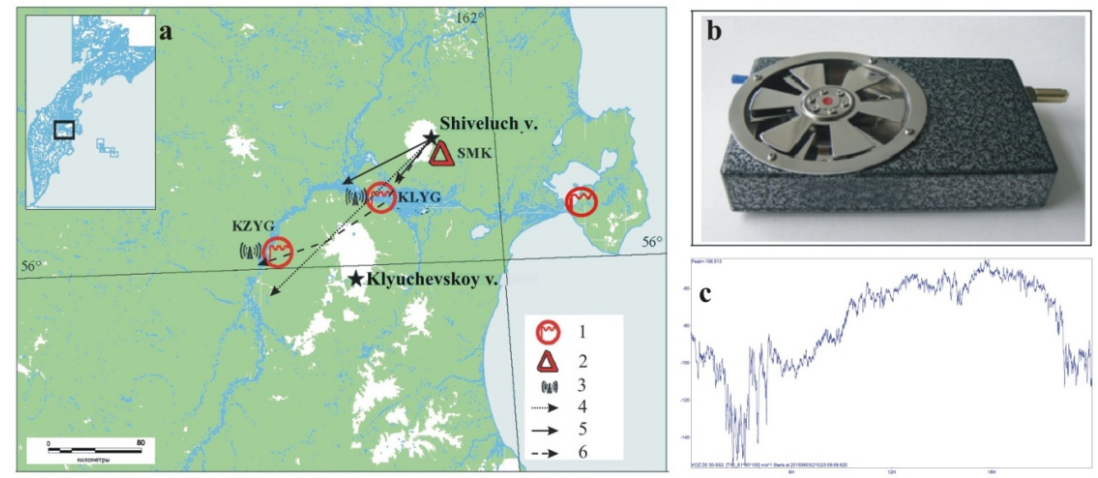

Fig. 1. a - a scheme of the location of PG registration points in the area of the Northern Group of Volcanoes and the route of eruptive clouds from the eruptions of the Shiveluch Volcano that had a response to PG; b- electrostatic fluxmeter «EF-4»; c- AEF variation diurnal record.

1-fluxmeter, 2- seismic station, 3- infrasound station; eruptive cloud motion trajectories during the eruptions on 4- 14.12.2014, 5-16.12.2016, 6-14.06.2017.

\section{PG diurnal variation features in Kamchatka peninsula}

Many papers are devoted to the investigation of PG diurnal variation. It is believed that the diurnal variation had been studied quite well, though, measurement results of PG diurnal variations in different parts of the globe during fair weather conditions differ significantly from each other. PG average diurnal values depend on latitude. They are maximal in middle latitudes and minimal by the equator and in the Polar Regions and differ in value by about three times.

In order to detect the unitary variation at KZYG site, we chose the days corresponding to fair weather conditions (wind velocity $5-7 \mathrm{~m} / \mathrm{s}$, without precipitation). Then the diurnal data (recorded with the sampling frequency of $100 \mathrm{~Hz}$ ) were processed by «DIMAS» interactive software. Averaging was carried out with the window of 600 seconds followed by decimation to one sample per 10 minutes. The chosen data array was grouped according to seasons (Fig. 2).

In winter and autumn times, the curves for two years (2014 and 2015) have weak correlation. Whereas, for spring and autumn periods, stable correlation is typical (Fig. 2). For winter time, the minimum falls at about 7 o'clock and the maximum is at about 16-20 o'clock (Fig. 2a). For other seasons, the minimum falls at $4-5$ o'clock and the maximum is at 18-19 o'clock (Fig. 2 b,c,d). The PG average seasonal values and root-mean-square deviations $(\sigma)$ are presented in Table 1.

Just like for «Paratunka» observatory located on the eastern coast of Kamchatka peninsula, the PG least values are characteristic for summer and spring periods (90-110 $\mathrm{V} / \mathrm{m}$ ) and the maximum values for winter and autumn times. PG seasonal dependence is determined by radon inflow into the near-ground layer of the atmosphere due to the decrease of soil upper layer permeability in winter time. It causes near-ground layer ionization decrease owing to the decrease of radon inflow into the atmosphere. 

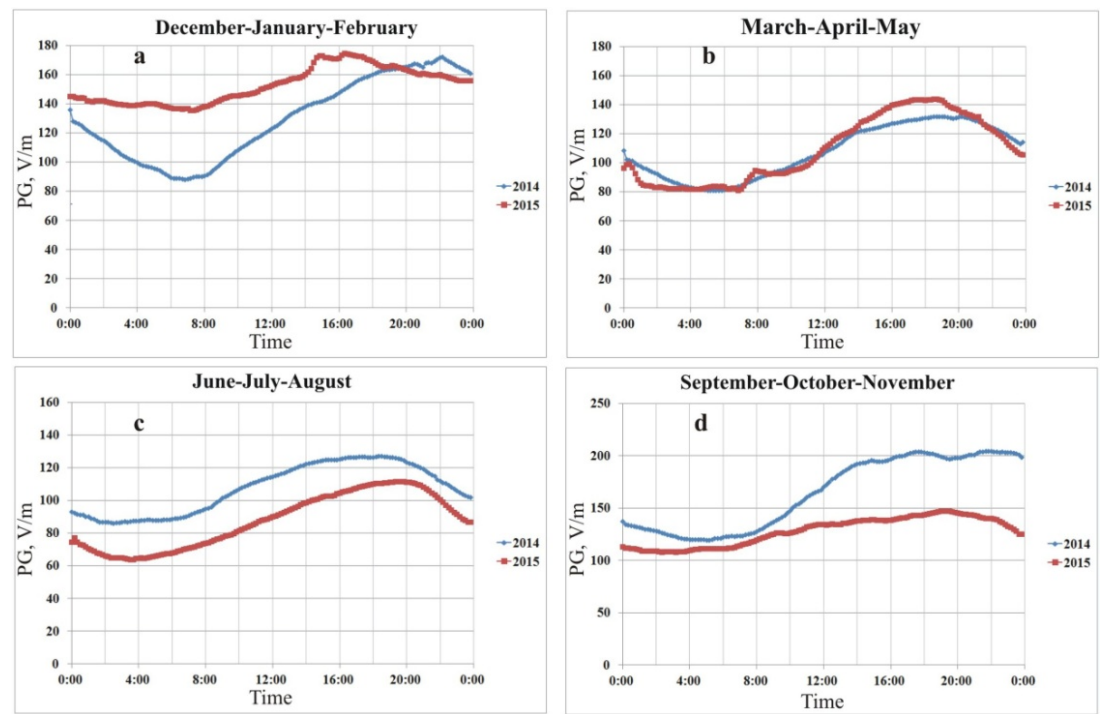

Fig. 2. Averaged graphs of PG diurnal variation for 2014 and 2015: a - first quarter; b second quarter; $\mathrm{c}-$ third quarter; $\mathrm{d}-$ fourth quarter.

Table 1. PG average quarter values and root-mean-square deviations.

\begin{tabular}{|c|c|c|c|c|c|c|c|c|}
\hline season & \multicolumn{2}{|c|}{ winter } & \multicolumn{2}{c|}{ spring } & \multicolumn{2}{c|}{ summer } & \multicolumn{2}{c|}{ autumn } \\
\hline year & 2014 & 2015 & 2014 & 2015 & 2014 & 2015 & 2014 & 2015 \\
\hline$P G, \mathrm{~V} / \mathrm{m}$ & 142 & 165 & 121 & 122 & 107 & 87 & 177 & 141 \\
\hline$\sigma, \mathrm{V} / \mathrm{m}$ & 28 & 12 & 18 & 23 & 15 & 17 & 34 & 13 \\
\hline
\end{tabular}

Unfortunately, applying this method for processing, we could not detect subtleties of the diurnal variation. We should mention that, owing to the geographical location of Kamchatka peninsula, AEF UT-variation falls within the morning terminator time. The terminator effect masks the UT-variation. The authors of the paper [7] succeeded to show the overlapping of these two effects on PG variation based on the data of $1998-2006$ obtained at «Paratunka» observatory, IKIR FEB RAS, $\left(\lambda=158,25^{\circ} \mathrm{E} ; \phi=52.9^{\circ} \mathrm{N}\right)$ for the days with fair weather conditions.

\section{Response in PG field during eruptive cloud passage from explosive eruptions of Shiveluch volcano}

Signals associated with the response in PG on eruptive cloud passage were selected on the basis of analysis of eruption dynamics according to the data of geophysical and satellite monitoring (realized by Kamchatkan Branch of the Federal Research Center "United Geophysical Service of the RAS") of Shiveluch volcano activity. It is provided by the following: radiotelemetric seismic (RTSS) and infrasound station network located near the active volcanoes (Fig. 1); monitoring of thermal anomalies by space images; visual and video observations. The closest RTSS «Semkorok» (SMK) is located $10 \mathrm{~km}$ to the South- 
East from Siveluch volcano. Explosive earthquake record gives us the information on the eruption beginning.

Data of balloon sounding, which is carried out twice a day at «Klyuchi» meteorological observatory of Kamchatka Administration on Hydrometeorology and Environment Monitoring data, give us the possibility to determine the propagation direction and velocity of eruptive clouds from explosive eruptions (http://www.esrl.noaa.gov/raobs/intl/intl2000.wmo). Volcanic lightning coordinates determined by WWLLN network data are one more method to trace an eruptive plume $[5,8]$. Such a data complex allows us to detect the disturbances in PG associated with eruptive ash-gas plume passage.

The extrusive dome on the most northern of Kamchatka active volcanoes, the Shiveluch volcano $\left(56^{\circ} 47^{\prime} \mathrm{N}, 157^{\circ} 56^{\prime} \mathrm{E}\right)$, has the height of $2500 \mathrm{~m}$ above the sea level. It has been forming for more than 50 years after the catastrophic eruption of 1956. During the latest decay, extrusive-explosive eruptions are characteristic for it. They are determined by magma slow ejection and dome formation which are accompanied periodically by strong ash explosions. For some of them, an eruptive cloud reaches the tropopause height $(\sim 10 \mathrm{~km}$ above the sea level), and sometimes, during corresponding wind directions, ash falls in Klyuchi and Kozyrevsk villages.

During the period of continuous observations over PG variations from 2014 to 2017, three cases were recorded when eruptive clouds from Shiveluch volcano explosions passed by the PG observation sites (Fig. 1, Table 2) that was promoted by fair weather conditions and corresponding wind direction.

Table 2. Parameters of PG signals recorded at ground sites during eruptive cloud passage from Shiveluch volcano eruptions.

\begin{tabular}{|c|c|c|c|c|c|c|c|c|c|c|}
\hline \multirow{2}{*}{$№$} & \multirow{2}{*}{ Date } & \multirow{2}{*}{$\mathrm{t}_{0}$} & \multicolumn{4}{|c|}{ KZYG } & \multicolumn{5}{|c|}{ KLYG } \\
\cline { 4 - 10 } & & polarity & $\begin{array}{c}\mathrm{PG}, \\
\mathrm{V} / \mathrm{m}\end{array}$ & $\begin{array}{c}\Delta \mathrm{t}, \\
\text { min. }\end{array}$ & polarity & $\begin{array}{c}\mathrm{PG}, \\
\mathrm{V} / \mathrm{m}\end{array}$ & $\begin{array}{c}\Delta \mathrm{t}, \\
\text { min. }\end{array}$ & $\begin{array}{c}\delta, \\
\mathrm{gr} / \mathrm{m}^{2}\end{array}$ \\
\hline 1 & 14.12 .2014 & $10: 17: 55$ & \multicolumn{3}{|c|}{170} & 85 & \multicolumn{3}{c|}{ Site did not work } \\
\hline 2 & 16.12 .2016 & $22: 31: 32$ & \multicolumn{2}{|c|}{ Cloud passed by } & - & -1249 & 51 & 20 \\
\hline 3 & 14.06 .2017 & $16: 26: 37$ & \multicolumn{2}{|c|}{+} & +1082 & 140 & $\begin{array}{c}- \\
+\end{array}$ & $\begin{array}{c}-5877 \\
+4820\end{array}$ & $\begin{array}{c}40 \\
34\end{array}$ & $\sim 300$ \\
\hline
\end{tabular}

Note. $\mathrm{t}_{0}$ is the time of eruption beginning, ${ }_{\Delta} \mathrm{t}$ is the signal duration, $\delta$ is the amount of ash per 1 squ.m.

Clear beginnings of two anomalies (12:04 and 13:10) of the total duration of $\sim 1.5$ hour are observed 1 hour and 46 minutes after the Siveluch volcano eruption on 16.11.2014 at $10: 18^{3^{*}}$ on PG record at KZYG site. Meteorogical values did not change significantly during this period that indicates fair weather conditions. At a maximum, $\mathrm{PG}$ reaches +70 $\mathrm{V} / \mathrm{m}$ (Fig. 4a). Fair weather conditions give the ground to consider PG variations as a consequence of eruptive plume electrisation, the trajectory of which passed $25 \mathrm{~km}$ to the east of KZYG site at the height of 9-10 and $12 \mathrm{~km}$ [5].

On December 16, 2016 at 22:31 an explosive eruption occurred on Shiveluch volcano. Based on the seismic signal intensity, the eruptive cloud height was estimated to be $5.6 \mathrm{~km}$ above the sea level. About 2 hours after it, ash fall with intensity of $20 \mathrm{~g} / \mathrm{m}^{2}$ was observed in Klyuchi village located $48 \mathrm{~km}$ to the South of Shiveluch volcano (azimuth is 30 ).

$3 \quad{ }^{*}$ Hereinafter UT 
The ash was of small fraction which propagated at the heights of $2.5 \div 3.0 \mathrm{~km}$ in South South-Western direction according to wind stratification. Whereas, at the heights of more than $5 \mathrm{~km}$, the eruptive cloud propagated in the West - South-Western direction that was recorded by satellite images. Ash fall in Klyuchi was accompanied by sharp decrease in $\mathrm{PG}$, the value of which in a maximum was $-1230 \mathrm{~V} / \mathrm{m}$ and the duration was 45 minutes (Fig. 4b). Such an PG response indicates that ash cloud represented by small fraction carried powerful negative charge.

During Shiveluch volcano eruption on June 14, 2017, successful combination of wind direction and fair weather conditions was observed. It allowed us to record PG variations during eruptive cloud passage in Klyuchi and Kozyrevsk villages.

Based on the record of seismic signal at RTSS SMK, the eruptive cloud height was estimated to be $12 \mathrm{~km}$ above the sea level. The character of seismic and acoustic signals records indicates explosive character of the eruption. Compared to the previous eruption, significantly greater amount of ash was emitted into the atmosphere during this event. It is indicated by large PG values at both KLYG and KZYG sites (Fig. 4 c,d). The time of signal arrival, in case of its duration of one hour and fifteen minutes at KLYG site, agrees both with atmosphere wind stratification obtained by atmosphere height balloon sounding in Klyuchi village and with satellite image analysis (HIMAWARI-8) (Fig.5a,b,c). Ring formation of an eruptive cloud with the diameter of $70 \mathrm{~km}$ during the first hour after the eruption was also determined by the latter. Fig. $5 \mathrm{~d}, \mathrm{e}, \mathrm{f}$ show the fragments of video observation where the eruptive cloud approaches and «covers» Klyuchi village.

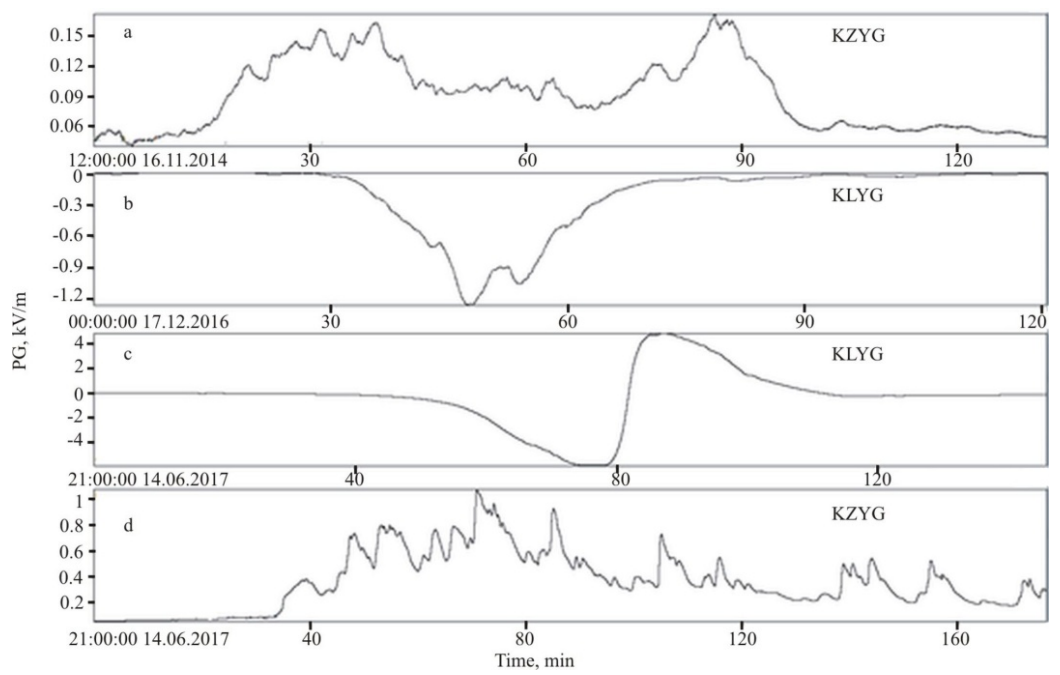

Fig. 3. PG response recorded by ground fluxmeter during eruptive cloud passage from Shiveluch volcano explosive eruptions: a - KZYG, 14.12.2014 ; b - KLYG, 16.12.2016; c - KLYG, 14.06.2017; d-KZYG, 14.06.2017. 


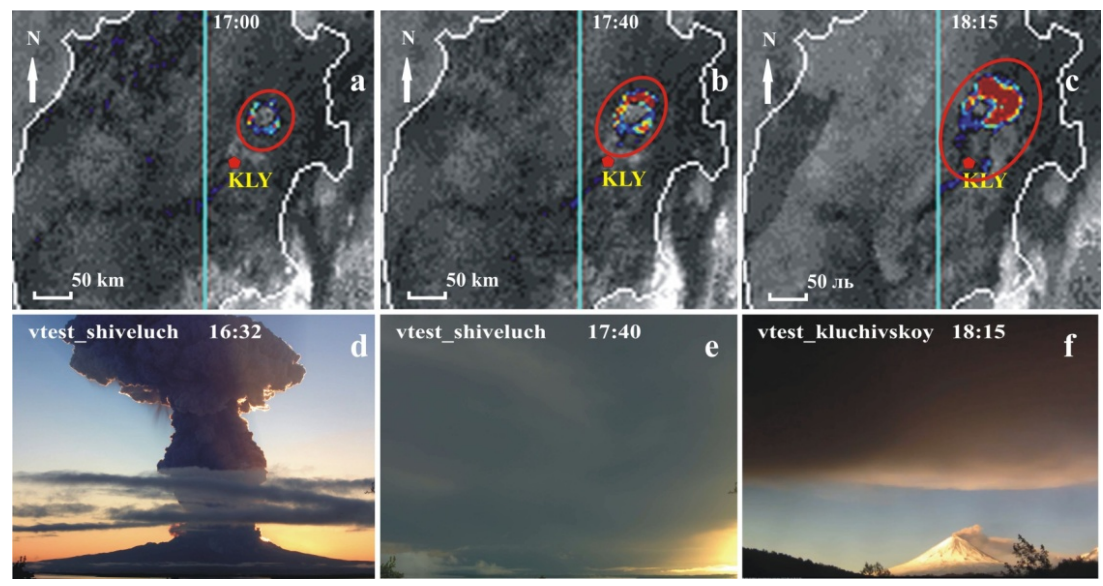

Fig. 4 a, b, c - satellite images (HIMAWARI-8) of an eruptive cloud from Shiveluch volcano eruption. The data were obtained in real-time mode at Uniskan-36 receiving site installed at the Institute of Volcanology and Seismology FEB; d, e, f - video observation of Shiveluch and Klyuchevskoy volcanoes.

Significant amount of ash of $\sim 300 \mathrm{~g} / \mathrm{m}^{2}$, which fell at KLYG site at the distance of 45 $\mathrm{km}$ from the volcano, agrees with the amplitude large excursion of bipolar signal $-5<\mathrm{PG}<6$ $\mathrm{kV} / \mathrm{m}$ (Fig. 4 c). According to the basic models [9] and based on the signal form, we can assume that the eruptive cloud charge represented a horizontal dipole the axis of which is oriented along the motion. During larger particle fall, negative PG was recorded and then aerozol component passage was observed. It had positive charge.

Just like in the first case, the unipolar signal from eruptive cloud plume at KZYG had positive charge. The anomaly lasted for more than three hours with PG $\max =1000 \mathrm{~V} / \mathrm{m}$ (Fig. 4 d).

\section{Conclusions}

Volcanic explosive eruptions on Kamchatka peninsula are a natural factor which causes the formation of electric structures of local scale. The papers [4,5] investigated volcanic cloud electrization but the mechanism of these complicated electric formations has not been studied well by the present. Thus, we hope that PG recording in the region of the Northern Group of volcanoes, where eruptions often occur, will allow us to obtain significant volume of experimental data which will give the possibility to investigate signal forms and its relation with volcanic explosion genesis.

The paper was supported by RFBR Grant No. 18-35-00175\18.

\section{References}

1. I.M. Imyanitov, Free atmosphere electricity. Lenigrad, (1965). 
2. I.M. Imyanitov, N.S. Shifrin, Physics-Uspekhi (Advances in Physical Sciences). T.LXXVI, I.4. pp.593-642 (1962).

3. M.J. Rycroft,S.Israelsson,C. Price, J.Atmos.Sol.-Terr.Phys.62, C.15631576(2000).

4. Williams E.R., .Atmos.Res.91, C. 140-152(2009).

5. Firstov P.P., Akbashev R.R., Holzworth R., Cherneva N.V., Shevtsov B.M. Izvestiya. Atmospheric and Ocean Physics. V.53. No. 1. pp. 29-37 (2017).

6. Efimov V.A., Oreshkin D.M., Firstov P.P., Akbashev R.R., Seismic Instrumentation. V. 49. No. 4. pp.35-46 (2013).

7. Kuznetsov V.V., Cherneva N.V., Bulletin of Kamchatka Regional Association «Educational-Scientific Center», Earth Sciences. V.1(11). pp. 89-97 (2008).

8. Shevtsov B.M., Firstov P.P., Cherneva N.V., Holzworth R. H., AkbashevR.R., Nat. Hazard Earth Syst. Sci. №3, V. 16. pp. 871-874. doi:10.5194/nhessd-16-871-2016(2016).

9. E.A. Ponomarev, N.V. Cherneva, P.P. Firstov, Geomagnetism and Aeronomy. V. 51. No. 3. pp. 405-411 (2011). 